\title{
Dose evaluation for paediatric chest $x$-ray examinations in Brazil and Sudan: low doses and reliable examinations can be achieved in developing countries
}

\author{
K E M Mohamadain ${ }^{1,6}$, L A R da Rosa ${ }^{2}$, A C P Azevedo ${ }^{1}$, M R N Guebel A $^{3}$ \\ M C B Boechat ${ }^{4}$ and F Habani ${ }^{5}$ \\ ${ }^{1}$ FIOCRUZ—Escola Nacional de Saúde Pública-CESTEH, Rua Leopoldo Bulhões 1480, \\ Manguinhos, 21041-210 Rio de Janeiro, Brazil \\ 2 Departamento de Física Médica, Instituto de Radioproteção e Dosimetria, \\ Comissão Nacional de Energia Nuclear, 22780-160 Rio de Janeiro, Brazil \\ ${ }^{3}$ Instituto de Pediatria e Puericultura Martagão Gesteira, UFRJ, 21490-910 Rio de Janeiro, Brazil \\ ${ }^{4}$ FIOCRUZ-Instituto Fernandes Figueira, Rio de Janeiro, Brazil \\ ${ }^{5}$ Physics Department, Faculty of Sciences, Khartoum University, Khartoum, Sudan \\ E-mail: acpa@ensp.fiocruz.br
}

Received 21 October 2003

Published 1 March 2004

Online at stacks.iop.org/PMB/49/1017 (DOI: 10.1088/0031-9155/49/6/012)

\begin{abstract}
Radiation protection in paediatric radiology deserves special attention since it is assumed that children are more sensitive to radiation than adults. The aim of this work is to estimate the entrance skin dose (ESD), the body organ dose (BOD) and the effective dose $(E)$ for chest $\mathrm{x}$-ray exposure of paediatric patients in five large units, three in Sudan and two in Brazil, and to compare the results obtained in both countries with each other and with other values obtained by some European countries. Two examination projections have been investigated, namely, postero-anterior (PA) and antero-posterior (AP). The age intervals considered were: $0-1$ year, $1-5$ years, 5-10 years and 10-15 years. The results have been obtained with the use of a software called DoseCal. Results of mean ESD for the age interval 1-5 years and AP projection are: $66 \mu$ Gy (Instituto de Pediatria e Puericultura Martagão Gesteira-IPPMG Hospital), 41, 86 and $68 \mu \mathrm{Gy}$ (Instituto Fernandes Figueira-IFF Hospital), $161 \mu \mathrm{Gy}$ (Omdurman Hospital), $395 \mu \mathrm{Gy}$ (Khartoum Hospital) and $23 \mu \mathrm{Gy}$ (Ahmed Gasim Hospital). In the case of the IFF Hospital, the results refer, respectively, to rooms 1,2 and for the six mobile equipments. The reference dose values given by the European Guidelines were exceeded in the Khartoum Hospital whilst in all the other hospitals results obtained were below CEC reference values and comparable with the results found in Sweden, Germany,
\end{abstract}

${ }^{6}$ On leave from Physics Department, Faculty of Sciences, Sudan University of Science and Technology, Khartoum, Sudan. 
Spain and Italy. The mean $E$ for the same age interval was $11 \mu \mathrm{Sv}$ in the IPPMG, 6, 15 and $11 \mu \mathrm{Sv}$ in the IFF, respectively for rooms 1,2 and the 6 mobiles, $25 \mu \mathrm{Sv}$ in the Omdurman Hospital, $45 \mu \mathrm{Sv}$ in the Khartoum Hospital and $3 \mu \mathrm{Sv}$ in the Ahmed Gasim Hospital. These are some examples of the large discrepancies that have been detected in this survey.

\section{Introduction}

In 1998, the Brazilian Sanitary Surveillance and the Ministry of Health of Brazil (1998) published the decree 453 establishing radiation protection guidelines for diagnostic radiology in medicine and odontology. Among the legal exigencies contained in the decree, the establishment of quality assurance programmes (QAP) is mandatory in all medical institutions that use ionizing radiation. In the field of odontology, the Instituto de Radioproteção e Dosimetria (IRD), Brazil, has been developing a very important programme since 1980 (da Rosa et al 2001) with good results.

In Sudan, the National Assembly in 1996, issued the Sudan Atomic Energy Commission (SAEC) Act. Under this Act, a policymaking Board was established by the Council of Ministers. The SAEC Board, within its mandate, established the Regulatory Authority Radiation Protection Technical Committee (RPTC). It is a national committee responsible for the development of the radiation protection legal framework, licensing procedures, policy making and approving inspections.

QAP and quality control initiatives in general diagnostic radiology have been developed in several countries in the past years, mainly in Europe (Leitlinien 1989, DIN 1985, Stender and Stieve 1986). However, the need for special QAP for paediatric patients were first realized early in the 1980s (da Silva 1999, Fendel et al 1985, Fendel 1990). The main goals were to improve the diagnostic information and to reduce the patient dose to a minimum; the ALARA principle (ICRP 1977). The efforts towards QA in paediatric radiology were at first dominated by the principle of justification and also by the concepts of 'efficacy/efficiency' (Fendel et al 1985, 1986). The WHO Report 757 compiled such principles for a number of common diseases in paediatrics and emphasized the term 'rational use of diagnostic imaging' (WHO 1987). The second important principle of 'optimization' (Fendel et al 1989) is discussed in the document 'quality criteria for diagnostic radiographic images in paediatrics' (CEC 1992) and an earlier developed document for adults, 'quality criteria for diagnostic radiographic images' (CEC 1990).

Justification for radiographic requests, standardization of procedures and optimization of protection measures are key principles in the protection of individuals exposed to ionizing radiation, especially children.

There is substantial evidence to suggest that children are more susceptible to the effects of ionizing radiation than adults. As a consequence of the longer life expectation, this places an added burden on staff to attain the best possible results every time. Likewise, the probability that there may be late radiation effects is also higher. The effects of exposures to ionizing radiation are dependent on the age at which exposure occurs. Exposure during childhood results in a likely two- or three-fold increase in lifetime risk for certain detrimental effects, including solid cancers, compared to that in an adult (United Nations Scientific Committee on the Effects of Atomic Radiation Sources Effects and Risks of Ionizing Radiation 2000). For the above-mentioned reasons, quality assurance in paediatric radiology is of major importance. 
Therefore, close attention should be paid to improve the diagnostic information, reducing the child's doses as much as possible.

Wide variations in patient doses up to a factor of 100 for radiation exposure for the same procedure have been reported in the literature (Shrimpton et al 1986, Faulkner and Corbett 1998). Reference dose levels provide a framework to reduce this variability (Contento et al 1998, Warren-Forward and Millar 1995, Wall 1996). Variations of dose within a hospital emphasize the importance of QAP so that inconsistencies and errors in technique and equipment can be discovered early, reducing, therefore, the variation in dose to patient.

A study in Malaysia ( $\mathrm{Ng}$ et al 1998) showed that it is possible to achieve much a tighter control on patient dose variation, demonstrating factors from 4.6 to 11.6. It is worth noting that all hospitals in the Malaysian survey carried out a QAP. The reasons for dose variations are very complex and difficult to identify. However, high doses are frequently associated with low $\mathrm{kV}$, high $\mathrm{mAs}$ and low filtration.

There is considerable evidence (Schneider 1995, Almen and Mattsson 1995, Geleijns et al 2000, Lopez et al 2000, Martin et al 1993, Hart and Shrimpton 1991) that substantial reductions are possible without detriment to the patient. Consistently high departamental doses will result in either an acceptable justification for the dose or revisions in technique or equipment to bring radiation doses in line with other hospitals (CEC 1996).

The reasons for dose variation are multifactorial: patient weight, exposure factors, radiological technique, focus to film distance (FFD), film-screen speed, equipment type and processing performance (Warren-Forward 1995). Weight restrictions can minimize the contribution of patient size to the mean dose variability (NRPB 1990). From this point of view, the methods can be classified into two categories: methods leading to a pure reduction of the mAs without modification of the beam quality (e.g., improving the film developing conditions, reducing the optical density (OD) of the film or increasing the speed class of the film/screen combination) and methods leading to modifications of the dose distribution within the patient by modifying the beam quality ( $\mathrm{kV}$ and/or filtration). Vice versa, $E$ can be influenced by the field size without necessarely modifying the ESD. The doses of ultimate interest in radiation protection are those to the most radiosensitive organs within the body. Therefore, all resources much be employed to avoid high doses in these organs. This can be achieved in chest X-rays, for example, by replacing an AP (antero-posterior) by a PA (postero-anterior) projection in girls to reduce the doses to breasts as well as to thyroid.

\section{Materials and method}

The aim of this work is to estimate the entrance skin dose, the body organ doses for 29 body organs and the effective dose for chest $\mathrm{x}$-ray exposures of paediatric patients and also to compare these results with the published values of the European Commission. Two projections have been studied, PA and AP. Because of shortage of standard size patients, it is possible to take all patients available in the measurement period and take the average dose as results as the outcome for a standard-sized patient. This will give a reasonable idea of the dose, provided that the number of patients is not too small; say a minimum of ten patients. However, for paediatric patients this is a difficult approach, especially for newborns due to the large variations in body weight.

This study was carried out in five paediatric units, namely the Instituto de Puericultura e Pediatria Martagão Gesteira that belongs to the Federal University of Rio de Janeiro, the Instituto Fernandes Figueira belonging to FIOCRUZ, in Brazil and three hospitals in Sudan, one in the city of Omdurman (Omdurman Hospital) and two in Khartoum city, namely 
Ahmed Gasim and Khartoum Hospital. The age intervals considered were: $0-1,1-5,5-10$ and 10-15 years. These age intervals were chosen since many results in the literature (Rruiz et al 1991, Gallini et al 1992) follow this protocol. The reason for choosing these two countries was that this work was part of the PhD Thesis of a Sudanese student who performed part of her experimental work in Brazil. This favourable and peculiar situation, involving two non first world countries motivated us to perform a study comparing patient doses in both countries, mainly due to the opportunity to have someone in Sudan. It is also important to mention that this was the first time that data for paediatric patients have been evaluated in Sudan.

The three hospitals in Sudan are of medium size (around 140 beds each), however they assist approximately 8400 patients per month. In Brazil, the IFF hospital is also of medium size with 70 beds and 1000 patiens per month. The IPPMG has around 50 beds and around 1000 patients per month. For each patient, the age, sex, weight and technical parameters of exposure (tube voltage, current, time product, focus to skin distance) were recorded.

Eleven X-ray machines were used in this work. They are all analogue systems and used without grids. Film-screen combination (speed) were 400. The x-ray equipments used in Sudan were FB-GT 22 (Ahmed Gasim Hospital), Siemens (Khartoum Hospital) and GEC Beaver (Omdurman Hospital). In Brazil, a RORIX was used in the IPPMG. In the IFF, a RORIX and six mobile equipments have been used, namely two FNX-85, one FNX-90 and three Mediroll-15. The $\mathrm{kV}$ was changed according to the type of examination and patient age, and varied from 36 to $81 \mathrm{kV}$ for AP projection, and from 36 to $96 \mathrm{kV}$ for PA projection. The $\mathrm{kV}$ values mentioned are nominal values. Differences between these values and real values may have occurred.

The patient anthropometrical data and technical parameters used were collected at the time of the examination. Only films that were considered suitable for diagnosis by the radiographer were accepted for this study in both countries. This ensured that all dose levels used were representative of diagnostic image. Image quality was fully comparable in the two Brazilian hospitals and suitable for diagnostic purposes. While all radiographs were found to be diagnostically acceptable, major differences in technique were evident reflecting the disparity in experience among staff at the different institutions. The rejection rate ranged from 10 to $15 \%$.

The dose values were obtained with the use of the DoseCal software that provides the ESD, the BOD as well as $E$. This software is designed for both, adults and children data. The use of software packages to perform patient doses is a modern resource in dosimetry and is being widely used in hospitals (Kyriou et al 2000, Cook et al 1998, Davies et al 1997). The calculation of ESD from output measurements and exposure factors is a realistic alternative method for dosimeter measurements such as for example measurements with thermoluminescent dosimeters (TLD). The software used in this work was specially developed for the evaluation of these doses. It was developed by the Radiological Protection Center of Saint Georges' Hospital, London, and generously donated for the elaboration of this research work. It is a computer-based system by which patient doses can be determined from exposure factors recorded at the time of the examination.

The development of practical methods for patient dose assessment in paediatric radiology is furthermore desirable since the QAP including patient dosimetry are a legal requirement nowadays in Brazil and in Sudan.

For the DoseCal software, the tube output (in $\mathrm{mGy} \mathrm{mAs}^{-1}$ ) of all $\mathrm{x}$-rays machines was measured using calibrated ionization chambers: Radcheck Plus X-rays exposure meter, model 06-526 in the IPPMG, Radcal Model 2025 in the IFF and a Gammex Dose Rate model 06-526 in the Sudanese hospitals. 
Table 1. ESD and $E$ for AP projection and age ranges 0-1, 1-5 and 5-10 years for the five hospitals in Brazil and Sudan.

\begin{tabular}{|c|c|c|c|c|c|c|c|}
\hline Age (years) & A Gasim & Khartoum & Omdurman & IPPMG & IFF (room 1) & IFF (room 2) & IFF (mobile) \\
\hline \multicolumn{8}{|l|}{$0-1$} \\
\hline \multicolumn{8}{|l|}{ ESD $(\mu \mathrm{Gy})$} \\
\hline Mean & 20 & 330 & 146 & 45 & 32 & 74 & 50 \\
\hline $\mathrm{SD}$ & 3 & 51 & 35 & 5 & 7 & 19 & 38 \\
\hline $\mathrm{CV} \%$ & 15 & 15 & 24 & 11 & 22 & 26 & 76 \\
\hline Min & 17 & 279 & 98 & 35 & 17 & 45 & 1 \\
\hline $\operatorname{Max}$ & 23 & 446 & 230 & 57 & 50 & 149 & 267 \\
\hline Median & 20 & 314 & 130 & 47 & 30 & 65 & 28 \\
\hline Sample size & 6 & 6 & 10 & 8 & 12 & 12 & 99 \\
\hline$E(\mu \mathrm{Sv})$ & 3 & 51 & 21 & 8 & 6 & 15 & 7 \\
\hline \multicolumn{8}{|l|}{$1-5$} \\
\hline \multicolumn{8}{|l|}{ ESD $(\mu \mathrm{Gy})$} \\
\hline Mean & 23 & 395 & 161 & 66 & 41 & 86 & 68 \\
\hline SD & 2 & 49 & 39 & 27 & 7 & 23 & 57 \\
\hline $\mathrm{CV} \%$ & 9 & 12 & 24 & 41 & 17 & 27 & 84 \\
\hline Min & 16 & 349 & 63 & 41 & 25 & 65 & 13 \\
\hline Max & 28 & 448 & 259 & 136 & 65 & 165 & 269 \\
\hline Median & 22 & 350 & 154 & 48 & 38 & 73 & 31 \\
\hline Sample size & 11 & 22 & 18 & 13 & 12 & 25 & 39 \\
\hline$E(\mu \mathrm{Sv})$ & 3 & 45 & 25 & 11 & 6 & 15 & 11 \\
\hline \multicolumn{8}{|l|}{$5-10$} \\
\hline \multicolumn{8}{|l|}{ ESD $(\mu \mathrm{Gy})$} \\
\hline Mean & - & - & - & - & 38 & 101 & 47 \\
\hline SD & - & - & - & - & 2 & 39 & 36 \\
\hline $\mathrm{CV} \%$ & - & - & - & - & 5 & 39 & 76 \\
\hline Min & - & - & - & - & 32 & 51 & 19 \\
\hline $\operatorname{Max}$ & - & - & - & - & 40 & 252 & 154 \\
\hline Median & - & - & - & - & 38 & 83 & 26 \\
\hline Sample size & - & - & - & - & 7 & 11 & 7 \\
\hline$E(\mu \mathrm{Sv})$ & - & - & - & - & 6 & 16 & 8 \\
\hline
\end{tabular}

Once the tube potential, the tube current, the exposure time and the focus to skin distance are known, formula 1 gives the ESD (Davies et al 1997):

$$
\mathrm{ESD}=\text { Output } \times\left(\frac{\mathrm{kV}}{80}\right)^{2} \times\left(\frac{100}{\mathrm{FSD}}\right)^{2} \times \mathrm{mAs} \times \mathrm{BSF} .
$$

Where Output is the output (in $\mathrm{mGy} \mathrm{mAs}^{-1}$ ) of the x-rays tube at $80 \mathrm{kV}$ at a distance of $1 \mathrm{~m}$ normalized to $10 \mathrm{mAs}, \mathrm{kV}$ the tube potential (in $\mathrm{kV}$ ), $\mathrm{mAs}$ the product of the tube current (in $\mathrm{mA}$ ) and the exposure time (in seconds), FSD the focus to skin distance (in $\mathrm{cm}$ ) and BSF is the back scatter factor.

\section{Results and discussion}

The results of ESD, BOD and $E$ for the chest x-rays examinations, obtained in five hospitals, are tabulated according to the age group, $\mathrm{kV}$ and $\mathrm{mAs}$ for the two projections $\mathrm{AP}$ and PA and are presented in tables 1-8. ESD values were obtained for standard working conditions prior to any corrective action being taken. The AP projection was not used for the 10-15 years range since children are generally able to stand up, while PA projection has not been used for 
Table 2. ESD and $E$ for PA projection and age ranges $1-5,5-10$ and $10-15$ years for the five hospitals in Brazil and Sudan.

\begin{tabular}{|c|c|c|c|c|c|c|}
\hline Age (years) & A Gasim & Khartoum & Omdurman & IPPMG & IFF (room 1) & IFF (room 2) \\
\hline \multicolumn{7}{|l|}{$1-5$} \\
\hline \multicolumn{7}{|l|}{ ESD ( $\mu \mathrm{Gy})$} \\
\hline Mean & - & - & - & 33 & 31 & 81 \\
\hline SD & - & - & - & 10 & 8 & 10 \\
\hline $\mathrm{CV} \%$ & - & - & - & 30 & 26 & 12 \\
\hline Min & - & - & - & 21 & 17 & 72 \\
\hline Max & - & - & - & 69 & 43 & 95 \\
\hline Median & - & - & - & 28 & 34 & 74 \\
\hline Sample size & - & - & - & 13 & 11 & 5 \\
\hline$E(\mu \mathrm{Sv})$ & - & - & - & 4 & 6 & 9 \\
\hline \multicolumn{7}{|l|}{$5-10$} \\
\hline \multicolumn{7}{|l|}{ ESD ( $\mu \mathrm{Gy})$} \\
\hline Mean & 24 & 279 & 233 & 31 & 41 & 118 \\
\hline SD & 3 & 67 & 160 & 7 & 11 & 40 \\
\hline $\mathrm{CV} \%$ & 12 & 24 & 7 & 22 & 27 & 34 \\
\hline Min & 19 & 209 & 88 & 21 & 31 & 82 \\
\hline Max & 28 & 498 & 843 & 44 & 68 & 179 \\
\hline Median & 23 & 233 & 125 & 28 & 31 & 94 \\
\hline Sample size & 8 & 10 & 10 & 10 & 11 & 5 \\
\hline$E(\mu \mathrm{Sv})$ & 31 & 2 & 23 & 3 & 4 & 14 \\
\hline \multicolumn{7}{|l|}{$10-15$} \\
\hline \multicolumn{7}{|l|}{ ESD $(\mu \mathrm{Gy})$} \\
\hline Mean & 21 & 320 & 159 & 65 & - & 119 \\
\hline SD & 3 & 50 & 36 & 26 & - & 27 \\
\hline $\mathrm{CV} \%$ & 14 & 16 & 23 & 40 & - & 23 \\
\hline Min & 15 & 233 & 100 & 26 & - & 91 \\
\hline Max & 25 & 437 & 231 & 97 & - & 146 \\
\hline Median & 23 & 320 & 150 & 75 & - & 119 \\
\hline Sample size & 8 & 8 & 8 & 7 & - & 5 \\
\hline$E(\mu \mathrm{Sv})$ & 11 & 1 & 15 & 6 & - & 13 \\
\hline
\end{tabular}

Table 3. Average values of ESD and $E$ for the six mobile x-ray equipments in the IFF Hospital.

\begin{tabular}{lccc}
\hline & Neonates $(<3 \mathrm{~kg})$ & $(0-1)$ year & $(1-5)$ years \\
\hline ESD $(\mu \mathrm{Gy})$ & & 54 & 70 \\
Mean & 35 & 39 & 57 \\
SD & 26 & 72 & 81 \\
CV\% & 74 & 6 & 13 \\
Min & 0.5 & 255 & 268 \\
Max & 156 & 28 & 32 \\
Median & 28 & 42 & 56 \\
Sample size & 37 & 10 & 12 \\
$E(\mu$ Sv $)$ & 7 & &
\end{tabular}

the $0-1$ year range because babies at these ages are not able to sit or stand up. In the IFF, the mobile equipment has been used only for AP projection. 
Table 4. Average radiographic parameters and patient data for AP projection and age ranges 0-1, 1-5 and 5-10 years in the five hospitals in Brazil and Sudan.

\begin{tabular}{|c|c|c|c|c|c|c|c|c|c|c|c|c|}
\hline \multirow[b]{2}{*}{ Hospital } & \multicolumn{4}{|c|}{$0-1$ year } & \multicolumn{4}{|c|}{$1-5$ years } & \multicolumn{4}{|c|}{$5-10$ years } \\
\hline & $\begin{array}{l}\text { Age } \\
\text { (month) }\end{array}$ & $\begin{array}{l}\text { Weight } \\
(\mathrm{kg})\end{array}$ & $\begin{array}{l}\text { Voltage } \\
(\mathrm{kV})\end{array}$ & $\mathrm{mAs}$ & $\begin{array}{l}\text { Age } \\
\text { (year) }\end{array}$ & $\begin{array}{l}\text { Weight } \\
(\mathrm{kg})\end{array}$ & $\begin{array}{l}\text { Voltage } \\
(\mathrm{kV})\end{array}$ & $\mathrm{mAs}$ & $\begin{array}{l}\text { Age } \\
\text { (year) }\end{array}$ & $\begin{array}{l}\text { Weight } \\
(\mathrm{kg})\end{array}$ & $\begin{array}{l}\text { Voltage } \\
(\mathrm{kV})\end{array}$ & $\mathrm{mAs}$ \\
\hline \multicolumn{13}{|l|}{ A Gasim } \\
\hline Mean & 5.88 & 5.50 & 40 & 2.1 & 2.3 & 9.6 & 40 & 2.6 & - & - & - & - \\
\hline SD & 3.24 & 1.83 & 3 & 0.3 & 0.6 & 1.83 & 3.87 & 0.24 & - & - & - & - \\
\hline $\mathrm{CV} \%$ & 55 & 33 & 8 & 14 & 26 & 19 & 10 & 9 & - & - & - & - \\
\hline Min & 0.96 & 3.00 & 36 & 1.8 & 1.8 & 6 & 37 & 2.4 & - & - & - & - \\
\hline Max & 12 & 9.00 & 43 & 2.4 & 4.0 & 16 & 51 & 3 & - & - & - & - \\
\hline Median & 5.76 & 5.50 & 40 & 2.1 & 1.9 & 9 & 37 & 2.4 & - & - & - & - \\
\hline Sample size & 6 & 6 & 6 & 6 & 11 & 11 & 11 & 11 & - & - & - & - \\
\hline \multicolumn{13}{|l|}{ Khartoum } \\
\hline Mean & 6 & 4.4 & 36 & 4.7 & 2.2 & 8.7 & 36.2 & 5.8 & - & - & - & - \\
\hline SD & 2.4 & 0.7 & 0 & 0.7 & 0.9 & 1.9 & 0.3 & 0.8 & - & - & - & - \\
\hline $\mathrm{CV} \%$ & 40 & 16 & 0 & 15 & 41 & 22 & 1 & 14 & - & - & - & - \\
\hline Min & 2.88 & 3.5 & 36 & 4 & 1 & 4 & 36 & 5 & - & - & - & - \\
\hline $\operatorname{Max}$ & 12 & 6 & 36 & 6.4 & 5 & 12 & 38 & 8 & - & - & - & - \\
\hline Median & 4.8 & 4 & 36 & 4.5 & 1.5 & 9 & 36 & 6.4 & - & - & - & - \\
\hline Sample size & 6 & 6 & 6 & 6 & 22 & 22 & 22 & 22 & - & - & - & - \\
\hline \multicolumn{13}{|l|}{ Omdurman } \\
\hline Mean & 8.76 & 5.40 & 54.40 & 7.20 & 3.2 & 11.7 & 59.5 & 9.4 & - & - & - & - \\
\hline $\mathrm{SD}$ & 3 & 1.18 & 3.20 & 1.44 & 1.4 & 3.9 & 4.1 & 2.1 & - & - & - & - \\
\hline CV\% & 34 & 22 & 6 & 20 & 44 & 33 & 7 & 22 & - & - & - & - \\
\hline Min & 1.92 & 3 & 50 & 6 & 1.32 & 4.5 & 50 & 6 & - & - & - & - \\
\hline $\operatorname{Max}$ & 12 & 8 & 60 & 10 & 5 & 20 & 70 & 20 & - & - & - & - \\
\hline Median & 9.78 & 5 & 54.5 & 6 & 3 & 12 & 60 & 9 & - & - & - & - \\
\hline Sample size & 10 & 10 & 10 & 10 & 18 & 18 & 18 & 18 & - & - & - & - \\
\hline \multicolumn{13}{|l|}{ IPPMG } \\
\hline Mean & 6 & 6.3 & 65.0 & 6.3 & 2.8 & 14.7 & 69.2 & 7.2 & - & - & - & - \\
\hline SD & 4.8 & 2.2 & 2.3 & 0.0 & 0.9 & 3.4 & 4.4 & 1.3 & - & - & - & - \\
\hline $\mathrm{CV} \%$ & 80 & 35 & 4 & 0 & 32 & 23 & 6 & 18 & - & - & - & - \\
\hline Min & 0.96 & 3.5 & 60 & 6.3 & 1.16 & 9 & 63 & 6.3 & - & - & - & - \\
\hline Max & 12 & 9 & 70 & 6.3 & 5 & 23 & 81 & 10 & - & - & - & - \\
\hline Median & 5.4 & 6.5 & 66 & 6.3 & 3 & 14 & 66 & 6.3 & - & - & - & - \\
\hline Sample size & 8 & 8 & 8 & 8 & 13 & 13 & 13 & 13 & - & - & - & - \\
\hline \multicolumn{13}{|l|}{ IFF (room 1) } \\
\hline Mean & 6 & 6.8 & 62.8 & 3.8 & 2.5 & 11.7 & 70.7 & 3.2 & 6.5 & 18.6 & 74.6 & 2.5 \\
\hline SD & 3.6 & 3.0 & 6.6 & 1.1 & 1.1 & 1.8 & 4.3 & 0.9 & 1.2 & 3.8 & 1.3 & 0.0 \\
\hline $\mathrm{CV} \%$ & 60 & 44 & 11 & 29 & 44 & 15 & 6 & 28 & 18 & 20 & 2 & 0 \\
\hline Min & 0.96 & 2.4 & 52 & 2.5 & 1 & 8.8 & 63 & 2.5 & 5 & 12.9 & 70 & 2.5 \\
\hline $\operatorname{Max}$ & 12 & 18 & 75 & 5 & 4.75 & 17 & 75 & 5 & 10 & 25 & 77 & 2.5 \\
\hline Median & 4.8 & 6.2 & 63 & 4 & 2.12 & 11.15 & 72.5 & 2.5 & 6.16 & 18 & 75 & 2.5 \\
\hline Sample size & 12 & 12 & 12 & 12 & 12 & 12 & 12 & 12 & 7 & 7 & 7 & 7 \\
\hline \multicolumn{13}{|l|}{ IFF (room 2) } \\
\hline Mean & 4.8 & 8.1 & 68.1 & 2.5 & 2.9 & 12.4 & 70.5 & 2.7 & 6.9 & 21.9 & 67.9 & 4.7 \\
\hline SD & 2.4 & 3.2 & 2.6 & 0.0 & 0.8 & 2.7 & 3.0 & 0.3 & 1.0 & 7.1 & 5.9 & 3.2 \\
\hline $\mathrm{CV} \%$ & 50 & 40 & 4 & 0 & 27 & 22 & 4 & 11 & 14 & 32 & 9 & 68 \\
\hline Min & 1.2 & 3.3 & 63.0 & 2.5 & 1.1 & 7.0 & 60.0 & 2.5 & 5.2 & 11.0 & 55.0 & 2.5 \\
\hline $\operatorname{Max}$ & 12 & 21.8 & 79 & 2.5 & 4.64 & 18 & 86 & 5 & 9.08 & 40 & 75 & 12 \\
\hline Median & 3.84 & 8 & 67 & 2.5 & 3.08 & 11 & 70 & 2.5 & 6.56 & 23 & 70 & 2.5 \\
\hline Sample size & 12 & 12 & 12 & 12 & 25 & 25 & 25 & 25 & 11 & 11 & 11 & 11 \\
\hline
\end{tabular}




\begin{tabular}{|c|c|c|c|c|c|c|c|c|c|c|c|c|}
\hline \multirow[b]{2}{*}{ Hospital } & \multicolumn{4}{|c|}{$0-1$ year } & \multicolumn{4}{|c|}{$1-5$ years } & \multicolumn{4}{|c|}{$5-10$ years } \\
\hline & $\begin{array}{l}\text { Age } \\
\text { (month) }\end{array}$ & $\begin{array}{l}\text { Weight } \\
(\mathrm{kg})\end{array}$ & $\begin{array}{l}\text { Voltage } \\
(\mathrm{kV})\end{array}$ & $\mathrm{mAs}$ & $\begin{array}{l}\text { Age } \\
\text { (year) }\end{array}$ & $\begin{array}{l}\text { Weight } \\
(\mathrm{kg})\end{array}$ & $\begin{array}{l}\text { Voltage } \\
(\mathrm{kV})\end{array}$ & mAs & $\begin{array}{l}\text { Age } \\
\text { (year) }\end{array}$ & $\begin{array}{l}\text { Weight } \\
(\mathrm{kg})\end{array}$ & $\begin{array}{l}\text { Voltage } \\
(\mathrm{kV})\end{array}$ & $\mathrm{mAs}$ \\
\hline \multicolumn{13}{|l|}{ IFF (mobile) } \\
\hline Mean & 3.6 & 4.7 & 58.3 & 2.0 & 2.4 & 12.5 & 64.6 & 2.4 & 8.5 & 17.3 & 68.5 & 3.0 \\
\hline SD & 2.4 & 2.5 & 5.9 & 0.7 & 1.2 & 5.8 & 3.6 & 0.7 & 1.0 & 4.3 & 4.2 & 1.0 \\
\hline $\mathrm{CV} \%$ & 67 & 53 & 10 & 35 & 50 & 46 & 56 & 29 & 12 & 25 & 6 & 33 \\
\hline Min & 1.2 & 1.0 & 40.0 & 0.3 & 1.0 & 3.2 & 60.0 & 1.0 & 6.9 & 13.0 & 56.0 & 1.5 \\
\hline $\operatorname{Max}$ & 12 & 11.6 & 90.0 & 8.0 & 4.7 & 110.6 & 75.0 & 5.2 & 10.0 & 25.0 & 75.0 & 6.0 \\
\hline Median & 2.4 & 3.5 & 60.0 & 2.0 & 1.7 & 10.0 & 65.0 & 2.0 & 8.1 & 16.5 & 70.0 & 2.8 \\
\hline Sample size & 99 & 99 & 99 & 99 & 41 & 41 & 41 & 41 & 5 & 5 & 5 & 5 \\
\hline
\end{tabular}

Table 1 shows the statistical results of ESD and $E$ for the AP projection, in all five hospitals (for six rooms) and for the six mobile equipments. The minimum, maximum, SD (standard deviation), CV\% (percentual coefficient of variation), mean and median, as well as the sample size (number of patients) are presented. Table 2 shows similar results for the PA projection.

According to NRPB (1999), reference levels for (ESD) for AP and PA chest radiographs in children are: $50 \mu \mathrm{Gy}$ for newborns and 1 year old children, $70 \mu \mathrm{Gy}$ for 5 years old and $120 \mu \mathrm{Gy}$ for 10 years old children. It is somewhat difficult to compare these reference values with the present results, since in this case, age ranges were evaluated and from these ranges a mean value was calculated. NRPB, on the other hand, provides reference levels for defined ages (newborns, 1 year, 5 years and 10 years). However, NRPB (1999) serves as guidance, for the sake of comparison with our results. In tables 1 and 2, the results that are above the recommended limits are presented in bold. A wide dose distribution has been found.

For example, in table 1, for age range 0-1 year, in the IFF Hospital, the mobile equipment showed a minimum value of $1 \mu \mathrm{Gy}$ for the ESD, while in the Khartoum Hospital, for the same age interval ( $0-1$ year), the maximum ESD was $446 \mu \mathrm{Gy}$. Similarly, for the age range 1-5 years, the ESD varied from $13 \mu \mathrm{Gy}$ in the IFF (mobile equipment) to $448 \mu \mathrm{Gy}$ in the Khartoum Hospital. The mean values also showed a wide distribution. For the age range 0-1 year the ESD in the A Gasim Hospital was $20 \mu \mathrm{Gy}$ (mean value) whilst at the Khartoum Hospital it was $330 \mu \mathrm{Gy}$. Similarly, for the age interval 1-5 years, the mean value at the A Gasim Hospital was $23 \mu \mathrm{Gy}$ and at the Khartoum Hospital was $395 \mu \mathrm{Gy}$.

The A Gasim Hospital presented the lowest values for all age ranges probably due to the fact that it is a university hospital with new equipment. On the other hand, the Khartoum Hospital systematically presented the highest values. This can be accounted for by the fact that processing conditions in that hospital are poor and there is no sensitometric control of processors. Additionally, $x$-ray equipment is very old with deficient maintenance.

$E$ presented also a wide variation, ranging 3-51 $\mu \mathrm{Sv}$ for $0-1$ year, 3-45 $\mu \mathrm{Sv}$ for $1-5$ years and 6-16 $\mu$ Sv for 5-10 years.

In table 1, although CV values are in general similar, analysing the mean and median values for the $0-1$ year range, it is evident that the ESD values are quite different, although all the distributions are comparable, excepting the IFF in the case of mobile equipment. It is important also to mention that the sample size are also different. In the IFF Hospital the FSD is greater in room 1 than in room 2. This fact can explain the differences encountered within the same hospital. 
Table 5. Average radiographic parameters and patient data for AP projection and age ranges 0-1, 1-5 and 5-10 years in the five hospitals in Brazil and Sudan.

\begin{tabular}{|c|c|c|c|c|c|c|c|c|c|c|c|c|}
\hline \multirow[b]{2}{*}{ Hospital } & \multicolumn{4}{|c|}{$0-1$ year } & \multicolumn{4}{|c|}{$1-5$ years } & \multicolumn{4}{|c|}{$5-10$ years } \\
\hline & $\begin{array}{l}\text { Age } \\
\text { (year) }\end{array}$ & $\begin{array}{l}\text { Weight } \\
(\mathrm{kg})\end{array}$ & $\begin{array}{l}\text { Voltage } \\
(\mathrm{kV})\end{array}$ & mAs & $\begin{array}{l}\text { Age } \\
\text { (year) }\end{array}$ & $\begin{array}{l}\text { Weight } \\
(\mathrm{kg})\end{array}$ & $\begin{array}{l}\text { Voltage } \\
(\mathrm{kV})\end{array}$ & $\mathrm{mAs}$ & $\begin{array}{l}\text { Age } \\
\text { (year) }\end{array}$ & $\begin{array}{l}\text { Weight } \\
(\mathrm{kg})\end{array}$ & $\begin{array}{l}\text { Voltage } \\
(\mathrm{kV})\end{array}$ & mAs \\
\hline \multicolumn{13}{|l|}{ A Gasim } \\
\hline Mean & - & - & - & - & 8.2 & 20.6 & 51 & 3.3 & 12.14 & 29.71 & 52.86 & 3.43 \\
\hline $\mathrm{SD}$ & - & - & - & - & 1.3 & 3.5 & 4 & 0.3 & 1.27 & 4.04 & 1.88 & 0.24 \\
\hline $\mathrm{CV} \%$ & - & - & - & - & 16 & 17 & 8 & 9 & 10 & 14 & 4 & 7 \\
\hline Min & - & - & - & - & 6.5 & 16.0 & 42.0 & 3.0 & 10 & 25 & 50 & 3 \\
\hline $\operatorname{Max}$ & - & - & - & - & 10 & 25 & 57 & 3.6 & 14 & 36 & 56 & 3.6 \\
\hline Median & - & - & - & - & 8 & 18 & 52 & 3.6 & 13 & 30 & 54 & 3.6 \\
\hline Sample size & - & - & - & - & 8 & 8 & 8 & 8 & 8 & 8 & 8 & 8 \\
\hline \multicolumn{13}{|l|}{ Khartoum } \\
\hline Mean & - & - & - & - & 6.4 & 16.4 & 37.5 & 6.4 & 12.0 & 34.2 & 39.8 & 7.7 \\
\hline SD & - & - & - & - & 1.3 & 3.5 & 0.8 & 0.0 & 2.2 & 6.7 & 1.6 & 0.9 \\
\hline $\mathrm{CV} \%$ & - & - & - & - & 20 & 21 & 2 & 0 & 18 & 20 & 4 & 12 \\
\hline Min & - & - & - & - & 5.0 & 11.0 & 36.0 & 6.4 & 9.0 & 25.0 & 38.0 & 6.4 \\
\hline $\operatorname{Max}$ & - & - & - & - & 9.0 & 23.0 & 38.0 & 6.4 & 15.0 & 43.0 & 44.0 & 10.0 \\
\hline Median & - & - & - & - & 5.9 & 18.0 & 38.0 & 6.4 & 12.0 & 31.0 & 40.0 & 8.0 \\
\hline Sample size & - & - & - & - & 10 & 10 & 10 & 10 & 8 & 8 & 8 & 8 \\
\hline \multicolumn{13}{|l|}{ Omdurman } \\
\hline Mean & - & - & - & - & 7.6 & 19.7 & 68.3 & 11.6 & 12.8 & 28.6 & 69.6 & 12.6 \\
\hline SD & - & - & - & - & 1.0 & 2.8 & 3.3 & 2.9 & 1.2 & 4.4 & 3.9 & 2.0 \\
\hline $\mathrm{CV} \%$ & - & - & - & - & 13 & 14 & 4 & 25 & 10 & 15 & 6 & 16 \\
\hline Min & - & - & - & - & 6.0 & 16.0 & 63.0 & 8.0 & 10.1 & 20.0 & 63.0 & 10.0 \\
\hline $\operatorname{Max}$ & - & - & - & - & 10 & 30.0 & 78.0 & 20.0 & 15.0 & 40.0 & 78.0 & 16.0 \\
\hline Median & - & - & - & - & 7.2 & 18.0 & 66.0 & 10.0 & 12.6 & 28.0 & 70.0 & 12.0 \\
\hline Sample size & - & - & - & - & 10 & 10 & 10 & 10 & 8 & 8 & 8 & 8 \\
\hline \multicolumn{13}{|l|}{ IPPMG } \\
\hline Mean & 2.6 & 14.6 & 69.2 & 6.1 & 7.3 & 22.8 & 70.2 & 6.8 & 12.2 & 34.2 & 76.5 & 9 \\
\hline SD & 1.0 & 4.2 & 5.3 & 1.6 & 1.1 & 3.4 & 6.4 & 2.4 & 0.9 & 7.6 & 11.0 & 1 \\
\hline $\mathrm{CV} \%$ & 38 & 29 & 8 & 26 & 15 & 15 & 9 & 35 & 7 & 22 & 14 & 11 \\
\hline Min & 1.1 & 7.0 & 57.0 & 4.0 & 5.0 & 17.0 & 57.0 & 4.0 & 11.0 & 28.0 & 60.0 & 8 \\
\hline $\operatorname{Max}$ & 4.0 & 31.0 & 77.0 & 10.0 & 9.0 & 28.0 & 81.0 & 10.0 & 14.0 & 46.0 & 96.0 & 10 \\
\hline Median & 3.0 & 13.0 & 70.0 & 6.3 & 7.5 & 22.5 & 73.0 & 7.2 & 12.0 & 29.0 & 79.0 & 9 \\
\hline Sample size & 13 & 13 & 13 & 13 & 10 & 10 & 10 & 10 & 7 & 7 & 7 & 7 \\
\hline \multicolumn{13}{|l|}{ IFF (room 1) } \\
\hline Mean & 3.0 & 18.7 & 63.6 & 3.2 & 6.8 & 20.6 & 70.4 & 3.4 & - & - & - & - \\
\hline SD & 0.8 & 11.2 & 6.1 & 1.0 & 2.1 & 5.3 & 2.9 & 1.4 & - & - & - & - \\
\hline $\mathrm{CV} \%$ & 27 & 60 & 10 & 31 & 31 & 26 & 4 & 41 & - & - & - & - \\
\hline Min & 1.7 & 8.8 & 55.0 & 2.5 & 5.0 & 16.0 & 60.0 & 2.5 & - & - & - & - \\
\hline $\operatorname{Max}$ & 4.2 & 80.0 & 77.0 & 5.0 & 10 & 35.0 & 78.0 & 8.0 & - & - & - & - \\
\hline Median & 3.4 & 13.0 & 60.0 & 2.5 & 5.0 & 17.5 & 70.0 & 2.5 & - & - & - & - \\
\hline Sample size & 11 & 11 & 11 & 11 & 11 & 11 & 11 & 11 & - & - & - & - \\
\hline \multicolumn{13}{|l|}{ IFF (room 2) } \\
\hline Mean & 2.7 & 8.8 & 72.4 & 2.5 & 8.7 & 15.4 & 66.8 & 2.8 & 10.5 & 28.5 & 75.0 & 3.5 \\
\hline SD & 0.6 & 0.4 & 3.0 & 0.0 & 1.1 & 4.4 & 2.7 & 0.0 & 0.4 & 5.6 & 4.0 & 1.2 \\
\hline $\mathrm{CV} \%$ & 22 & 5 & 4 & 0 & 13 & 29 & 4 & 0 & 4 & 20 & 5 & 34 \\
\hline Min & 2.0 & 8.5 & 70.0 & 2.5 & 7.7 & 14.5 & 73.0 & 2.5 & 10.0 & 14.5 & 70.0 & 2.5 \\
\hline $\operatorname{Max}$ & 3.2 & 9.3 & 80.0 & 2.5 & 10 & 25.2 & 79.0 & 2.5 & 11.0 & 35.0 & 79.0 & 5.0 \\
\hline Median & 3.2 & 8.5 & 71.0 & 2.5 & 7.8 & 23.0 & 74.0 & 2.5 & 10.2 & 29.0 & 78.0 & 2.5 \\
\hline Sample size & 5 & 5 & 5 & 5 & 5 & 5 & 5 & 5 & 5 & 5 & 5 & 5 \\
\hline
\end{tabular}


Table 6. Body organ dose ( $\mu \mathrm{Gy})$ for AP and PA projections in Brazilian hospitals.

\begin{tabular}{|c|c|c|c|c|c|c|c|}
\hline \multirow{2}{*}{$\begin{array}{l}\text { Age } \\
\text { (years) }\end{array}$} & \multirow[b]{2}{*}{ Organs } & \multicolumn{2}{|c|}{ IPPMG } & \multicolumn{2}{|c|}{ IFF (room 1) } & \multicolumn{2}{|c|}{ IFF (room 2) } \\
\hline & & $\mathrm{AP}$ & PA & $\mathrm{AP}$ & PA & $\mathrm{AP}$ & PA \\
\hline \multirow[t]{5}{*}{$1-5$} & Breasts & 42 & 3 & 29 & 3 & 65 & 11 \\
\hline & Heart & 18 & 5 & 13 & 4 & 27 & 15 \\
\hline & Thyroid & 30 & 1.4 & 20 & 1.1 & 46 & 4.6 \\
\hline & Total bone & 16 & 11 & 10 & 10 & 23 & 31 \\
\hline & Trunk region & 13 & 7 & 9 & 6 & 21 & 18 \\
\hline \multirow[t]{5}{*}{$5-10$} & Breasts & & & 27 & 4 & 56 & 14 \\
\hline & Heart & & & 3 & 5 & 5 & 19 \\
\hline & Thyroid & & & 18 & 0.9 & 38 & 5.2 \\
\hline & Total bone & & & 7 & 11 & 15 & 34 \\
\hline & Trunk region & & & 7 & 8 & 15 & 25 \\
\hline
\end{tabular}

Table 7. Ranges of technical factors and output values for four mobile equipments in the IFF Hospital.

\begin{tabular}{llllllc}
\hline & & & & \multicolumn{2}{c}{ Output in $\mu \mathrm{Gy}$ at $50 \mathrm{kV}$} \\
\cline { 5 - 7 } Mobile equipment & $\mathrm{kV}$ & $\mathrm{mAs}$ & FSD & FSD & $\mathrm{mAs}$ & Output \\
\hline Equipment 1 & $50-80$ & $2-8$ & $50-110$ & 100 & 10 & 38 \\
Equipment 2 & $40-48$ & $0.3-0.5$ & $40-100$ & 71 & 10 & 80 \\
Equipment 3 & $60-90$ & $0.4-3$ & $50-120$ & 71 & 10 & 122 \\
Equipment 4 & $56-75$ & $1.5-12.5$ & $50-120$ & 71 & 10 & 79 \\
\hline
\end{tabular}

Table 8. ESD for two mobile equipments in the IFF Hospital with different outputs. Results are for chest, age range $0-1$ year and AP projection.

\begin{tabular}{lcl}
\hline $\operatorname{ESD}(\mu \mathrm{Gy})$ & Equipment 3 & Equipment 4 \\
\hline Mean & 62 & 30 \\
SD & 49 & 13 \\
CV\% & 79 & 43 \\
Min & 6 & 13 \\
Max & 267 & 70 \\
Median & 33 & 26 \\
Sample size & 30 & 8 \\
\hline
\end{tabular}

Table 2 shows similar results with variations in mean ESD from $24 \mu \mathrm{Gy}$ to $279 \mu \mathrm{Gy}$ in A Gasim and Khartoum hospitals respectively for the age interval 5-10 years and from $21 \mu \mathrm{Gy}$ to $320 \mu \mathrm{Gy}$ for the age interval $10-15$ years in the same hospitals.

Table 3 shows the average results for the ESD and $E$ for the six mobile equipments used in the IFF. Age ranges are: neonates (up to $3 \mathrm{~kg}$ of weight), 0-1 and 1-5 years old. The values of $E$ are all below the recommended limits found in the literature (NRPB 1999). For the AP projection it can be seen that the mAs varied from $2.0 \mathrm{mAs}$ (IFF mobile equipment) to $7.2 \mathrm{mAs}$ (Omdurman Hospital) for the age range $0-1$ year. For the age range 1-5 years, the mAs values ranged from $2.4 \mathrm{mAs}$ to $9.4 \mathrm{mAs}$.

Tables 4 and 5 show the statistical data with respect to patient anthropometrical data (age and weight), $\mathrm{kVp}$ and $\mathrm{mAs}$ for $\mathrm{AP}$ and $\mathrm{PA}$ projections, respectively. Wide varieties of technical parameters have been found, reflecting the lack of standardization of procedures. 


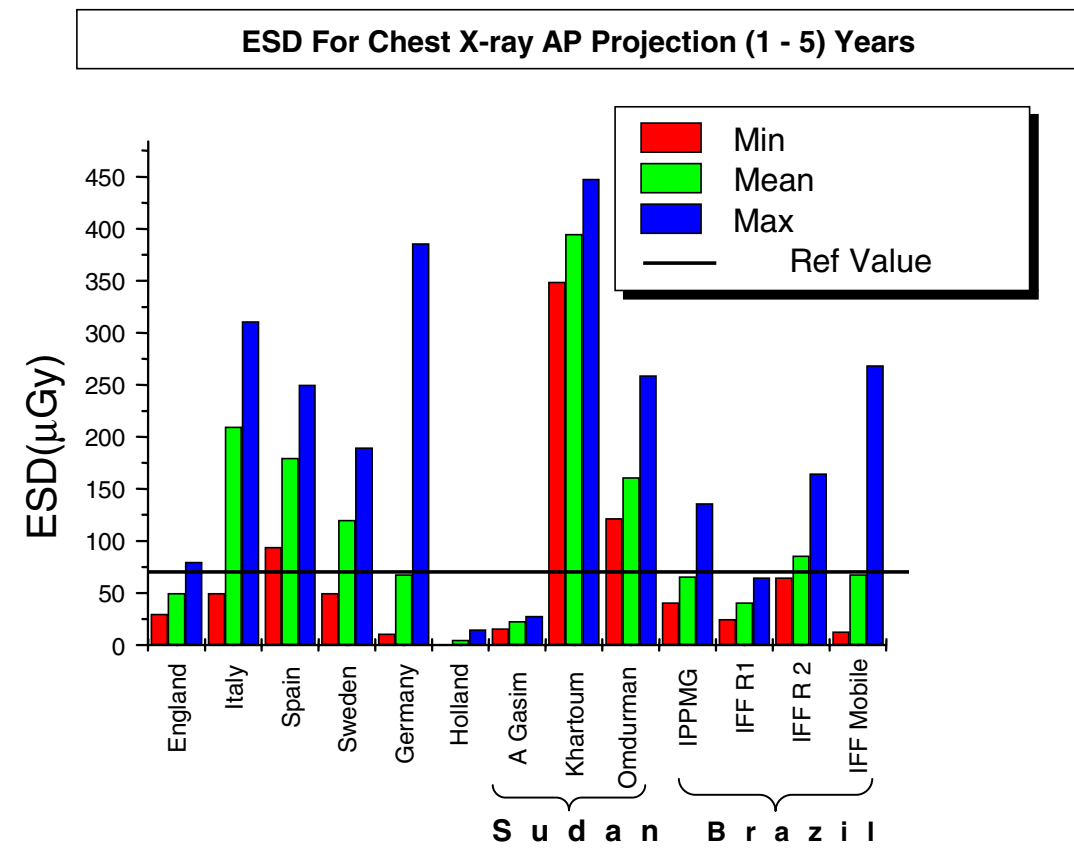

Figure 1. Minimum, maximum and mean values of ESD obtained in Brazil and Sudan, compared to the reference values and results of some European countries. The age range is 1-5 years and AP projection.

(This figure is in colour only in the electronic version)

For the PA projection and age range 5-10 it varied from $2.8 \mathrm{mAs}$ (IFF) to $11.6 \mathrm{mAs}$ (Omdurman Hospital) and for the age interval 10-15 years, it varied from $3.43 \mathrm{mAs}$ to $12.6 \mathrm{mAs}$.

In table 6, the BOD can be seen for the AP and PA projections respectively. It is seen that the AP projection delivers a high dose to the breasts and should be avoided whenever possible, specially for girls. The same applies for the thyroid.

Risk factors for patients are different from risk factors for the general population and workers, due to several reasons. The risk estimates derived by ICRP (NRPB 1999) refer to a general population, considering both sex, a typical age distribution and typical cancer mortality rates. However, the age distribution for the exposed population to diagnostic radiology procedures presents a tendency to older age groups. The predominance of old or ill persons in a population, theoretically, would reduce the risk of long-term effects, in comparison with a population of workers. On the other hand, considering a population of children, that risk would be larger. However, the ICRP (1991) and the ICRP (1996) do not consider these facts; as an example, the ICRP (1996), in its paragraph 22, states 'Despite the wide range of organ doses in radiology and the differences in age structure, the collective dose and the nominal detriment coefficients provide a reasonably good indicator of the detriment in a population exposed in diagnostic radiology and nuclear medicine'.

Figure 1 shows the minimum, maximum and mean values of ESD as compared to reference values and results from other European countries. Most values are comparable with the reference level adopted in Europe. The highest values come from Khartoum, Italy, Spain, Omdurman and IFF (room 2). Dose values measured in Rio de Janeiro are at the same levels 
as European results, except if compared with Dutch results which are very low and completely different from the other countries. Therefore they do not represent the European situation.

An example of radiographic technique, output values ( $\mathrm{kV}, \mathrm{mAS}$ and $\mathrm{FSD})$ and the respective ESD results in $\mu$ Gy are presented in tables 7 and 8 . This example is for the mobile equipment used in the IFF. Table 7 exemplifies the lack of standardization with respect to the radiographic technique. The most important factor in the increase of dose is the mAs and it can be seen that it ranges from $0.3 \mathrm{mAs}$ to $12.5 \mathrm{mAs}$. On the other hand, the output values that are needed for running the DoseCal software, directly influence in the final dose. The output values seen in table 7 vary from 38 to $122 \mu \mathrm{Gy}$. The variation of the above-mentioned factors result in variation of $\mathrm{ESD}, \mathrm{BOD}$ and $E$. An example of this variation is shown in table 8 where values of ESD for the age range $0-1$ year are presented for two different mobile equipments. Mean values are $30 \mu \mathrm{Gy}$ for one equipment and $62 \mu \mathrm{Gy}$ for the other equipment.

\section{Conclusions}

Results within Brazil are somewhat consistent while in Sudan, large differences were found. Therefore, a wide distribution of doses has been obtained. The reasons could be: the performance of the equipment and processors, radiographic techniques used in each hospital $(\mathrm{kVp}, \mathrm{mAs}$ and filtration), film-screen combination, use of grid and/or training and skill of the staff, and patient size.

The results of this study emphasize the necessity for the adherence to easily followed guidelines for the improvement of training and equipment in paediatric radiology. There is a large scope for dose reduction, not necessarily associated with high investments. Dose differences of two orders of magnitude, for the same type of examination, have been reported. Several mthods of dose reduction can be applied. However, not all of them influence the effective dose in the same proportion. Therefore, each department should implement the most appropriate/adequate method for its reality.

For all age ranges the Khartoum Hospital presents, systematically, the highest doses associated with low CV values, meaning that the doses applied in this hospital are always high, indicating a permanent problem, probably associated with equipments and/or processing conditions. On the other hand, the A Gasim Hospital presents the lowest dose values for all age ranges.

Sample size (number of patients) is not the same due to several factors, especially due to the limited time for data collection.

In the IFF, in room 2 , the doses are systematically higher (2-3 times) than they are in room 1 . The output of the equipment in room 2 was higher than the one of room 1 . This fact could be one of the reasons for the large differences in dose values.

It has been observed that high dose values are, generally, associated with high $\mathrm{mAs}$ values.

Ahmed Gasim is a paediatrics university hospital, with a very well-trained staff to work with neonates and children in general. The other two hospitals in Sudan considered in this work are general hospitals, not dedicated for paediatrics. Their staff have no special training to work with children and their equipments and procedures are, normally, adapted for adults.

In Brazil, the dose to the patient is, unfortunately, not yet considered as an important limiting factor in many departments. The most important parameter considered by the technicians is the image quality. Therefore, high mAs values are normally used in order to obtain a good image contrast, causing the delivery of higher, avoidable doses to the patient. This philosophy should be changed in order to consider not only the adequate quality for 
diagnosis of the radiography, attested by a radiologist but also, the dose delivered to the patient, which should be maintained as low as reasonably achievable (ALARA principle).

The present results do not reflect, necessarily, the Brazilian and Sudanese situations in paediatrics radiology, but only the situation of the hospitals evaluated in this work. The comparison with the results, obtained by some European countries, was presented only to give an idea about the performance of the Brazilian and Sudanese medical x-ray departments, as compared to typical present standards of hospitals in European developed countries.

The absorbed doses in chest radiography are lower compared to other paediatric x-ray projections. However, being chest the most common projection, it significantly contributes to the collective dose. The patients are also very young, so it is desirable to continue to optimize the paediatric chest radiography and to reduce the doses as much as reasonable. The ESD values evaluated for the different age intervals considered are comparable with the values found in Sweden, Germany, Spain and Italy and the reference dose level, except for the Khartoum Hospital. The possible explanation for this discrepancy is that in that hospital there is not yet an ongoing QAP. The x-rays tubes are also very old.

In our experince, a QAP organized on a central basis can be a useful instrument to reach every hospital, with the aim of improving and optimizing radiological practice.

Absolute values of $E$ are relatively low at all hospitals and below the international recommended limits (NRPB 1999, ICRP 1991, 1996, Hintenlang et al 2002).

There are potential advantages in using the effective dose in diagnostic radiology: patient exposure would be described by one single value, avoiding a complicated series of relevant organ doses. The effective dose is an easily manageable quantity, perhaps more adequate to compare similar exposure situations.

However, there are several drawbacks connected with the use of $E$ in diagnostic radiology (Drexler et al 1993): the validity of the basic assumptions underlying the concept of equivalent dose is questionable in this context. The linear dose-effect relationship which has to be assumed for considering mean organ doses cannot be assumed, as large dose gradients within single organs can occur. Additionally, the doses applied in diagnostic radiology may reach magnitudes where deterministic effects can occur. Using effective dose, one has to be aware that risk coefficients derived for a general or working population may not be valid in this situation and are, quite obviously, not appropriate for the age distribution of a general patient population. Therefore, if collective doses in diagnostic radiology are evaluated without considering age and sex specific risk coefficients, valuable information will be lost. ESD is a most realistic quantity in diagnostic radiology and one may have a large ESD but a low $E$.

\section{Acknowledgments}

The authors are indebted to the Radiological Protection Centre of Saint Georges' Hospital (London) for the authorization of use of the DoseCal software for patient dosimetry. We also acknowledge the financial support of: CAPES, The British Council, Federal University of Rio de Janeiro, Third World Organization for Women in Science, International Centre for Theoretical Physics (Italy), Fundação Oswaldo Cruz (FIOCRUZ) and Instituto de Radioproteção e Dosimetria-CNEN.

\section{References}

Almen A and Mattsson S 1995 Dose distribution in children at chest radiology Radiat. Prot. Dosim. 57 1-4, 463-7 Brazilian Sanitary Surveillance and the Ministry of Health of Brazil 1998 Diretrizes de Proteção Radiológica em Radiodiagnóstico Médico e Odontológico, Portaria 453 do Ministério da Saúde DOU 103, 01/06/98 
CEC 1990 Quality criteria for diagnostic radiographic images Working Document No XII/173/90, 2nd edn CEC 1992 Quality criteria for diagnostic radiographic images in paediatrics Working Document No XII/307/91

CEC 1996 European Guidelines on Quality Criteria for diagnostic radiographic images EUR 16260EN The European Commission

Cook V, Shah K, Pablot S and Kyriou J 1998 A Practice in the X Ray Imaging of Children St George's Hospital \& St Helier Hospital, London

Contento G et al 1998 A comparison of diagnostic radiology practice and patient exposures in Britain, France and Italy Br. J. Radiol. 61 143-52

da Rosa L A R, Maréchal M H H, Carlos M T and Feital J C 2001 Calibration of TL detectors for skin entrance dose postal quality control in dental radiology Proc. CD Regional Congress on Radiation Protection and Safety (Recife, Brazil)

da Silva E T 1999 Avaliação de Doses em Radiodiagnóstico Pediátrico MSc Thesis COPPE/UFRJ/Brazil (in Portuguese)

Davies M, McCallum H, White G, Brown J and Hlem M 1997 Patient dose audit in diagnostic radiography using custom designed software Radiography 3 17-25

DIN 6868/1 1985 Sicherung der Bildqualitaet in Roentgendiagnostik Betrieben; Allgemeines (Berlin: Beuth Verlag $\mathrm{GmbH})$

Drexler G, Panzer W, Petoussi N and Zankl M 1993 Effective dose-how effective for patients? Radiat. Environ. Biophys. 32 209-19

Faulkner K and Corbett R H 1998 Reference doses and quality in medical imaging Br. J. Radiol. 71 1001-2

Fendel H 1990 Symposium: The Status of Paediatric Radiology in Europe. The Principles for Rational Use and Optimisation of Diagnostic Imaging in Paediatrics: 27th Congress of ESPR (Munich)

Fendel H, Schneider K, Schäfer H, Bakowski C and Kohn M M 1985 Optimisation in pediatric radiology: are there specific problems for quality assurance in pediatric radiology? Technical and Physical Parameters for Quality Assurance in Medical Diagnostic Radiology: Tolerances, Limiting Values and Appropriate Measuring Methods (BIR 18) ed B M Moores et al (London: British Institute of Radiology) pp 159-65

Fendel H, Schneider K, Bakowski C, Glas J, Drews K and Kohn M M 1986 The efficacy of diagnostic radiation in paediatrics, 2nd Report (Bonn: Bundesministerium für Umwelt, Naturschutz und Reaktorsicherheit)

Fendel H, Schneider K, Bakowski C and Kohn M M 1985 Die Auswirkung Diagnostischer Strahlenanwendungen in der Kinderheilkunde: 1. Bericht (Bonn: Bundesministerium des Innern)

Fendel H, Schneider K, Bakowski C and Kohn M M 1989 Specific Principles for Optimisation of Image Quality and Patient Exposure in Paediatric Diagnostic Imaging (BIR 20) ed B M Moores et al (London: British Institute of Radiology) pp 91-110

Gallini R E, Belletti S, Berna V and Giugni U 1992 Radiat. Prot. Dosim. 43 41-7

Geleijns J, Broerse J and Van Vilet M 2000 Assessment of effective dose in pediatric radiology: a survey at 14 Dutch hospitals Radiat. Prot. Dosim. 90 1-2,135-40

Hart D and Shrimpton P C 1991 The significance of patient weight when comparing X ray room performance against guideline levels of dose Br. J. Radiol. 64 771-2

Hintenlang K M, Williams J L and Hintenlang D E 2002 A survey of radiation dose associated with pediatric plain-film chest X-ray examinations Pediatr. Radiol. 32 771-7

ICRP 1977 Recommendations of the International Commission on Radiological Protection Publication 26 (Oxford: Pergamon)

ICRP 1991 Recommendations of the International Commission on Radiological Protection Publication 60 (Oxford: Pergamon)

ICRP 1996 Recommendations of the International Commission on Radiological Protection Publication 73 (Oxford: Pergamon)

Kyriou J C, Newey V and Fitzgerald M C 2000 Patient Doses in Diagnostic Radiology at the Touch of a Button The Radiological Protection Centre, St George's Hospital, London, UK

Leitlinien B K 1989 der Bunderztekammer zur Qualitaetssicherung in der Roentgendiagnostik Deutschesrzteblat 86 1437-44

Lopez M, Morant J J, Geleijns K and Calzados A 2000 A regional dose and image quality survey for chest, abdomen and pelvis radiographs in pediatrics Radiat. Prot. Dosim. 190 1-2, 275-8

Martin C J, Darraigh C L, McKenzie G A and Bayliss A P 1993 Implementation of a programme for reduction of radiation doses and results achieved through increases in tube potential Br. J. Radiol. 66 228-33

$\mathrm{Ng} \mathrm{K-H} \mathrm{et} \mathrm{al} 1998$ Doses to patients in routine X ray examinations in Malaysia Br. J. Radiol. 71 654-60

NRPB 1990 Patient dose reduction in diagnostic radiology NRPB 1 no 3 (London: HM50)

NRPB 1999 Guidelines on Patient Dose to Promote the Optimization of Protection for Diagnostic Medical Exposures vol 10 (UK) p 1 
Rruiz M J, Gonzalez L, Vanõ E and Martinez A 1991 Measurement of radiation doses in the most frequent simple examiantion in paediatric radiology and its dependence on patient age Br. J. Radiol. 64 929, 933

Schneider K 1995 Evaluation of quality assurance in pediatric radiology Radiat. Prot. Dosim. 57 1-4, 119-23

Shrimpton P C et al 1986 A national survey of doses to patients undergoing a selection of routine X ray exposures in English hospitals $N R P B-R 200$ (London: HMTO)

Stender H S and Stieve F E 1986 Qualitätskontrolle in der Roentgendiagnostik (Stuttgart: Gustav Fischer Verlag)

United Nations Scientific Committee on the Effects of Atomic Radiation Sources Effects and Risks of Ionizing Radiation 2000 UNSCEAR 2000 Report vol II: Effects (New York, NY: United Nations)

Wall F 1996 Reference doses for diagnostic medical exposures Radiol. Manage. 18 22-9

Warren-Forward H M 1995 Patient dosimetry during chest radiography Radiat. Prot. Dosim. 57 441-4

Warren-Forward H M and Millar J S 1995 Optimization of radiological technique for chest radiography Br. J. Radiol. 68 1221-9

World Health Organisation-Study Group 1987 Rational Use of Diagnostic Imaging in Paediatrics (WHO Technical Report Series) 757 (Geneva: WHO) 